E.L.U.A., 5, 1988-1989, pp. 67-82

\title{
EL ALCANCE EXPLICATIVO DEL FUNCIONALISMO: SUS LIMITACIONES
}

\author{
LUIS J. EGUREN \\ (Universidad de Valladolid)
}

\section{Las críticas generativistas a las teorías sobre las funciones del lenguaje}

En las conclusiones a nuestro estudio sobre la relevancia lingüística de las jitanjáforas (Eguren, 1985: 232), resaltábamos cómo el lógico enfoque funcionalista adoptado en el mismo no forzaba una aceptación incondicional de todos y cada uno de los postulados de dicha tendencia teórica. Este escepticismo dimanaba de las dificultades que nos deparó el intento de situar -con mayor o menor fortuna- lo que denominábamos "función lúdica" del lenguaje entre las demás funciones reconocidas, y se ha visto reforzado al analizar en profundidad las posturas funcionalistas más radicales, que hacen derivar las funciones internas del lenguaje de sus funciones externas '. Explicitar nuestras discrepancias con el paradigma funcionalista es la tarea que acometemos en el presente trabajo, diferencias que coinciden con y se sustentan en las dos críticas fundamentales que la Gramática Generativa Transformacional (GGT) ha formulado a las teorías sobre las funciones externas del lenguaje: la indeterminación del concepto "función del lenguaje" y la pretendida subsidiariedad de la estructura con respecto a los usos-finalidades.

En primer lugar, para Chomsky (1968: 117; 1975: 88-120; 1977: 123; 1980:240 y sigs.) carece de sentido la extendida afirmación de que la función "central" del lenguaje sea la comunicación. Se emplea éste con multitud de propósitos igualmente relevantes -relevancia que descansa en el ángulo desde el que se enfoque el fenómeno-: establecer relaciones humanas, jugar, crear... y, sobre todo, servir de soporte al pensamiento. En opinión del lingüísta norteamericano, "no se ha conseguido aún sobrepasar taxonomías descriptivas al

"El término "función" denota, en tcoría lingüística, dos acepciones básicas: lunciones "del" lenguaje o de uso y funciones "cn" el lenguaje o estructurales -propiedades cxtrínsecas o intrínsecas, respectivamente, al análisis del lenguaje en sí mismo (Hymes, 1970: 167; 1984: 54 y sigs.). Las escuelas funcionalistas reciben su denominación, indistintamente, aunque de un modo más o menos interrelacionado, de ambos sentidos. Tan sólo el primero de cllos es el que aquí nos ocupa. 
tratar de las funciones del lenguaje" (Chomsky, 1975: 64) ${ }^{2}$.

Ahora bien, la actitud de Chomsky debe entenderse en sus justos términos. De ella no se deduce, como a menudo se ha afirmado, que la GGT desdene globalmente los planteamientos funcionalistas: "tales taxonomías pueden tener un valor considerable, a pesar de sus limitaciones...; han contribuido al análisis de la comunicación eficaz y han facilitado descubrimientos válidos sobre las propiedades semánticas de los enunciados." (Chomsky, 1975: 114 y 345$)$.

Lo que la GGT emprende es una fuerte idealización de su campo de estudio, excluyendo, metodológicamente, consideraciones -entre otras- sobre las funciones del lenguaje, en buena medida debido a la difícil (iimposible?) sistematización de este tipo de hechos.

En segundo lugar, la GGT sostiene que el "núcleo duro" de la estructura lingüística, representada en la mente, está establecido en el código genético de la especie: al menos esta parcela esencial de la estructura -el objeto de estudio de la GGT- sería independiente, estrictamente hablando, de los fines con yue se utiliza el lenguaje. Si queremos comprender, en consecuencia, la capacidad psico-biológica sobre la que se asienta el lenguaje humano, debemos preguntarnos qué es y no para qué sirve (Chomsky, 1968: 117).

De nuevo, esta posición no excluye que aspectos de la estructura tengan una base funcional. Así, Chomsky (1975: 90 y 348), rebatiendo la crítica de Searle de que la GGT separa drásticamente las estructuras sintácticas de funciones como la comunicación, le recuerda que nunca ha puesto en tela de juicio el que existan lazos significativos entre estructura y función, "a condición de ubicarlos en el nivel que corresponda".

Los imperativos de la comunicación han podido influir en la estructura del lenguaje, tanto en la evolución de la especie (filogénesis) como en las transformaciones sufridas por las lenguas particulares, pero -argumenta Chomsky (1975: 92-93; 1980:241)- observaciones de este tenor son excesivamente generales: de escasa ayuda le sirve al fisiólogo, para explicar la naturaleza del cuerpo humano, el que las exigencias de la locomoción subyacieran al hecho de que el hombre desarrollara piernas en lugar de alas. Mucha menor relevancia alcanzan incluso las soluciones funcionalistas en la explicación del "crecimiento" de los órganos -en este caso, de un "órgano mental" como el lenguaje- en los individuos concretos: el niño no adquiere reglas o representaciones lingüísticas en virtud de su función, así como no aprende a tener ojos porque es necesario ver. Desde una perspectiva ontogenética, lo pertinente es la información inscrita en el código genético, que determina la estructura (lingüística) del organismo (Chomsky, 1977: 131;1982: 29).

Chomsky reconoce, en cambio, que criterios funcionalistas -aún indeterminados y no vinculados necesariamente a la comunicación- perfilan algunos aspectos de la estructura. Las transformaciones sintácticas simplifican, probablemente, los procesos de memorización (Chomsky, 1977: 131); la estrategia perceptual del análisis de los enunciados establece, en parte, el carácter de las reglas lingüisticas (Chomsky, 1980: 241); los "filtros" -condiciones de buena formación de las estructuras patentes antes de recibir su interpretación. fonológicaquizás encuentren su rezón de ser en la reducción de la ambigüedad (Chomsky, 1982: 29).

${ }^{2}$ M. A. K. Halliday conviene con Chomsky en uste punto: no pucden enumerarse los usos del lenguaje de una manera sistemática y tampoco merece la pena hacerlo, ya que no habría manera de preferir una lista a otra (Halliday, 1970: 146; 1978: 62, 242; Kress, 1976: 29). De este "caos" funcional, Halliday ext rac sus tres metalunciones, con rellejo en la estructura lingüística. 
Ahondamos, a continuación, en ambas críticas con argumentos que las fortalecen: (a) la noción de "función del lenguaje" varía sustancialnente y, con ella, el número de las funciones y su jerarquización, dependiendo del marco teórico en el que surge; (b) principios básicos de la estructura lingúística -como los que propugna la Teoría del Ligamiento- no pueden sustentarse, de manera relevante, en consideraciones funcionalistas.

\section{La multiplicidad de taxonomías}

De igual modo que el concepto "función gramatical" (función interna) se refiere a realidades diversas según las tendencias, así mismo las funciones externas del lenguaje no son entendidas de manera homogénea por las escuelas lingüísticas.

Efectuamos, en este apartado, seis calas en las teorías sobre las funciones del lenguaje algunas de ellas, poco divulgadas-, ajustándonos a un criterio tanto lógico (su paulatina complicación) como cronológico (su sucesión relativa en el tiempo) ${ }^{3}$. En todos los casos mantenemos el mismo esquema: especificación del marco teórico, su correspondiente definición de función externa, diversidad en el múmero y la jerarquía de las funciones y reseña de las críticas al modelo.

(a) El "organon" de Bühler (1934) recoge ordenadamente un conjunto de ideas que pertenecen al clima intelectual de principios de siglo y que resaltan el plano expresivo del lenguaje y su plurifuncionalidad, v.g., Ogden y Richards (1923) y Gardiner (1951). Bühler amalgama concepciones psicologistas centradas en el acto de habla con aspectos primitivos de semiología y teoría de la comunicación. El lenguaje, en esta primera versión de las funciones externas, es un "organon (instrumento) para comunicar uno a otro algo sobre las cosas" y las funciones del lenguaje -representativa, expresiva y apelativa- se conciben indistintamente como "funciones semánticas del signo lingúístico complejo" -la representación, la expresión y la apelación- o como "momentos de aparición del signo" -símbolo, síntoma y señal, según su alternativa relación con los objetos, el emisor y el receptor-.

Estos estudios del primer tercio del siglo se interesan por los fenómenos de la lengua como perspectiva "externas", no lingúísticas, psicológicas (Bühler), sociológicas (Gardiner) o filosóficas (Ogden y Richards). En el caso de Bühler, la conciliación de influjos dispares (psicología, semiología y teoría de la comunicación), el precario desarrollo de las dos últimas disciplinas en su momento histórico y la simplificación de la rica variedad del lenguaje justifican matizaciones como las de García Calvo (1958) y Araya Goubet (1964) que añaden, respectivamente, una función lúdica y otra mostrativa a las reconocidas por Bühler, y críticas con respecto al uso inexacto de los términos semiológicos (símbolo, síntoma y señal) y a la falsa identificación entre los tres polos de la comunicación (objetos, emisor y receptor) y las

${ }^{3}$ Vial. Eguren (1985: (ap. 3) para una discusión extensa de las diferentes tcorías sobre las funciones del lenguaje. Evidentemente, eslas scis "calas" no agotan el campo de cstudio. Hemos escogido las teorías que más explícitamente definen la noción de "función del lenguaje" y elaboran taxonomías cerradas. La tcoría de los actos de habla -y, en conjunto, los "filósolos del lenguaje ordinario"- se acogen también a una concepción del lenguaje como acción en contexto que cumple determinadas finalidades. La ilimilada serie de géneros de actos de hablà enunciar. ordenar, preguntar, descar, prometer...- no hace sino reafirmar nuestra hipótesis de que el lenguaje humano puede ser utilizado con infinidad de propósitos difícilmente jerarquizables. 
tres personas gramaticales (Martínez Bonati, 1960).

(b) Morris (1946) identifica el signo con un estímulo que provoca respuestas y las funciones del lenguaje con las disposiciones para reaccionar ante los signos, con los propósitos hacia los que el signo encauza la conducta. Distingue este autor cuatro usos primarios de los signos -informativo, valorativo, incitativo y sistemático-, que equipara a cuatro facetas de la conducta y a un número semejante de signos en los diversos modos de significar: designadores para informar al organismo acerca de algo, apreciadores para ayudarle en su selección preferencial de objetos, prescriptores para provocar series de respuestas y formadores para organizar la conducta de los signos dentro de un todo determinado.

En realidad, Morris vierte las tres funciones de Búbler en un molde conductista y su aportación se limita a resaltar el papel de los signos formadores (conectores lógico-sintácticos). Prescindiendo de la dudosa validez del prisma conductista, la propuesta de Morris adolece de una deficiencia en la que incurrirán estudios posteriores ": designa con el mismo término de "función del lenguaje" fenómenos de naturaleza netamente lingúística -la función sistemática- y otros con un origen extralingúístico -sus otras tres funciones-.

(c) Jakobson (1960) presenta un modelo ampliado del de habla de Bühler bajo el influjo directo de la teoría de la comunicación. A los seis factores imprescindibles para todo hecho comunicativo -referente, destinador, destinatario, mensaje, canal y código- les corresponden seis funciones externas: referencial, emotiva, conativa, poética, fática y metalingüistica. Las funciones del lenguaje son, pues, orientaciones hacia uno de los polos de la comunicación y se entrecruzan -con la predominancia de una de ellas- en los textos.

La motivación implícita en este esquema es el interés de Jakobson por incluir la función poética, definida sobre bases formales -"la proyección del principio de equivalencia del eje de la selección en el eje de la combinación"- entre las demás funciones, conciliando, de este modo, los estudios literarios con los lingúisticos (Richards, 1972). Su originalidad reside, por tanto, en el agrupamiento conjunto de tres nuevas funciones al servicio de una caracterización lingúística de lo poético y no en el descubrimiento de las mismas: la función metalingüística posee un antecedente lógico-matemático, la función fática evoca la "comunión fática" de los estudios antropológicos de Malinowski (1923) y la función poética, entendida como revalorización de la forma, del mensaje, está ya presente en las directrices marcadas por el Círculo de Praga.

Precisamente, de lo que singulariza a la teoría de Jakobson nacen las puntualizaciones que ha recihido: el basarse en la teoría de la comunicación es calificado de no lingúístico; la pluralidad de fuentes en la elección de las funciones, necesitadas de una mayor jerarquización, es la causa de su heterogeneidad; el afán por conceder rango lingüístico a la función poética fuerza un imaginario equilibrio entre las funciones. Valgan, a modo de ejemplo, algunas objeciones al esquema de Jakobson desde dentro del mismo marco del estructuralismo funcionalista.

F. François (1965) destaca que no hay plasmaciones lingǘsticas particulares que distingan la función metalinguística de la referencial, que se detecta un cierto artificio en la correspondencia elementos de la comunicación - funciones y que está ausente una mínima

${ }^{4}$ Halliday se enfrenta a una dificultad semejante al asignar el mismo estatus feórico a su metafunción text ual que a las metafunciones ideativa e interpersonal. 
jerarquía de las mismas.

Trujillo (1976) considera que las funciones del lenguaje, lingüísticamente hablando, deben apoyarse en marcas formales objetivas, identificadoras de cada función. Con este criterio, establece una distinción entre funciones "primarias" -denotativa, expresiva y apelativay funciones "secundarias" ("ocasionales o superpuestas") -las tres restantes-.

Riffaterre (1971) refuerza el papel de lo poético por medio de su "función estilística", que consiste en la conexión de la intención del codificador con los efectos que el mensaje despierta en el descodificador. El resultado estilístico está en relación directa con la cantidad de información y ésta es inversamente proporcional al grado de previsibilidad de aparición de los signos en un contexto determinado: el mensaje, sobrecargado de datos desconocidos o sorprendentes para el receptor, queda resaltado. La función estilística no sería ya un refuerzo secundario de las demás funciones sino la función básica, una función que modula la intencionalidad de información de los demás -que las modifica- con intención de estilo.

(d) Para Martinet (1960: 14-16, 28-29; 1962: 16; 1964: 57; 1985: 22 y 25), la función esencial de las lenguas, aquella que configura su evolución y su estructura, es la comunicación, "la transmisión de la experiencia de una persona a otra". Junto a ella, se encuentra una gama de usos parciales o entremezclados: servir de vehículo al pensamiento, hablar sin interlocutor (soliloquio), expresar las propias emociones, embellecer la realidad, preguntar, mandar, llamar la atención sobre uno mismo, jugar...

D. François (1969) intenta regular este abigarrado repertorio de usos: la comunicación es la función central del lenguaje; la ausencia de comunicación -la expresión (soliloquio)- o su implementación con otro factor -el servir de soporte al pensamiento, las funciones estética y lúdica- caracteriza a los "papeles secundarios"; las seis funciones de Jakobson ("funciones 3" en su terminología) componen un subgrupo independiente, el de las focalizaciones que la propia comunicación realiza sobre los factores que la constituyen; la expresión y la apelación, finalmente, son "modalidades", no, funciones.

Como indicábamos al reproducir las críticas de Chomsky al funcionalismo, no parecen existir pruebas concluyentes que otorguen el rango de "primaria" a la función de comunicación sobre las demás. El posible influjo de la comunicación en la evolución y la estructura de las lenguas será revisado en el apartado siguiente y, en cualquier caso, ino impone también el pensamiento humano condiciones específicas sobre su estructuración lingüística?.

Incluso la detallada clasificación de D. François peca de arbitrariedad: ipueden equipararse la ausencia y la presencia de comunicación en la definición de los llamados "papeles secundarios"?; ¿son factores idénticos los que adjuntan a la comunicación la función estética y la función de soporte del pensamiento como para agruparlos bajo la misma etiqueta?; ies la denominación de "función 3". algo más que un elegante procedimiento de asimilación de la propuesta de Jakobson?.

(e) Las formulaciones de las funciones del lenguaje más sugerentes y teóricamente más firmes, aunque, paradójicamente, las menos difundidas, localizan el problema en el terreno donde puede resultar más fructífero, la sociolinguíística. M. A. K. Halliday y D. Hymes son dos hitos significativos de esta corriente.

Halliday $(1970,1973,1975$ a y b, 1978, 1981, 1985) contruye una síntesis original de diversas fuentes, tanto de lingüística autónoma como de sociolingüística: conjuga el modelo gramatical de Firth -en particular, su noción de "sistema"- con la estrecha relación entre funciones del lenguaje y funciones gramaticales que postulan los praguenses; por otra parte, 
las concepciones "extralingüísticas" de Bernstein y Malinowski anclan la descripción del sistema lingüístico en el entorno social. El resultado es su teoría sistemático-funcional.

Halliday concibe el lenguaje como un sistema de significados sociales, como un potencial de significación enclavado en un "contexto de cultura". Adquirirlo consiste en aprender a significar, es decir, en asimilar los usos del lenguaje y el potencial de significado social a ellos asociado.

Los usus del lenguaje o potencialidades de significación funcional -instrumental, regulador, interaccional, personal, heurístico, imaginativo e informativo- se solidifican en tres metafunciones o componentes funcionales altamente abstractos del sistema semántico, que recogen el potencial de significación común de las variedades de usos sociales del lenguaje y le conceden un reflejo lingüistico en el sistema gramatical ${ }^{5}$.

Sus tres metafunciones, con estatus de rasgos universales -aunque las categorías descriptivas se particularicen en cada lengua (Halliday, 1985: xiii)-, son la función ideativa, que sirve para expresar el contenido de la experiencia del hablante, la función interpersonal, que posibilita el establecimiento y la continuación de las relaciones sociales (función que agrupa las funciones expresiva y apelativa de Bühler) y la función textual, que permite al hablante construir textos, pasajes conexos de discurso vinculados a la situación.

La importancia teórica última de este modelo (Halliday, 1975b: 265) reside en que:

\begin{abstract}
debido a las bases funcionales del lenguaje, los signilicados particulares, concretos, que se expresan en situaciones colidianas se convierten, para el niño que aprende una lengua, en la lucnte primera para consiruir el contexto de cultura |... palabras y estructuras que sirven en alguna medida para calcgorizar el orden social y la parlicipación del niño en este orden |... De este modes, el lenguaje llega a ocupar el papel central en los procesos de aprendizaje social.
\end{abstract}

Su preocupación por explicar los mecanismos de transmisión de la cultura y de los valores de una sociedad a través del lenguaje otorga al funcionalismo de Halliday un interés indudable. Sin embargo, descubrimos , al menos, dos lagunas en su teoria: (a) Halliday (1975a) prescinde explicitamente de tomar partido en el debate entre innatistas y conductistas sobre la adquisición del lenguaje; ¿cómo dar cuenta, entonces, del carácter universal que confiere a sus metafunciones?; ¿son éstas meras generalizaciones o rasgos inherentes al lenguaje humano?. (b) La función textual no muestra el mismo nivel teórico que las funciones ideativa e interpersonal; es una función lingüística, instrumental para las otras dos, y no refleja ningún potencial de significado social ni es el resultado del desarrollo de los usos externos del lenguaje; este hecho nos indica un desajuste en el modelo de Halliday que apunta, en realidad, hacia la autonomía de los aspectos puramente textuales -y por ende, de los gramaticales- con respecto al entorno socio-cultural concreto ${ }^{\circ}$.

${ }^{5}$ Halliday (1975a) describe el proceso de desarrollo del lenguaje-adquisición de potencialidades de significación social- en un niño, Nigel, desde un primer momento claramente funcional aparcamientos unívocos de sonido y sentido con un use social- hasta el estado adulto tricsarático -fonología, sintaxis y léxico-scmántica-, caracterizado por tres melalunciones que se dan juntas en los textos.

"Halliday (1981: 138-145) habla también de un cuarto componente la función cognitiva- que tiene que ver con un conjunto específico de procedimientos estructurales, los conectores lógicos $(y, 0$, si...). Curiusamente, sólo en este texto, de entre los consultados, aparece esta función. Lo cicro es que la función cognitiva, netamente estructural 
(f) Hymes representa una rama de la sociolingüística que propugna la localización del lenguaje dentro de la cultura y la sociedad -la etnolingüistica o etnografía de la comunicación-, estudiando los actos de habla como integrantes de un sistema más general de actos comunicativos.

En su primera aproximación a las funciones del lenguaje, Hymes (1964) diseña una "guía" para el análisis etnográfico, retomando el modelo de Jakobson y ampliándolo con dos nuevos factores de la comunicación -el contexto y los sucesos en sí mismos- y dos nuevas funciones -contextual y metacomunicativa-. Las funciones focalizan cada componente y pueden ser específicas de los individuos y las culturas (etnografía).

En un segundo momento, Hymes (1967) elabora su esquema del acto del habla, que funciona como una "red heurística" para las descripciones, distinguiendo "dieciséis o diecisiete" factores: la forma del mensaje, su contenido, el contexto físico ("setting") y psicológico ("scene"), el hablante o emisor, el destinador, el oyente o receptor, el destinatario, los resultados ("outcomes"), las finalidades ("goals"), el tono ("key"), los canales, las variedades de habla -códigos, registros, dialectos-, las normas de interacción, las normas de interpretación o contexto de cultura, los géneros (poema, carta, conversación....)... Las funciones del habla son ahora relaciones entre los componentes y cada grupo social concede mayor énfasis a unos/as sobre otros/as como parte de la taxonomía de su sistema sociolingüístico.

Sin duda, estas "guías" o "redes heurísticas" ofrecen una utilidad considerable para la caracterización de los grupos sociales y lingüísticos. Sin embargo, la inexactitud en el número de factores en el acto de habla, la ausencia de jerarquización y la combinación indiscriminada de elementos prioritariamente lingüísticos -v.g., la forma del mensaje- con otros de naturaleza no lingüística -v.g., las normas de interacción-, por el momento, convierten la pretensión de Hymes de que asuman más adelante el estatus de rasgos universales en una declaración de principios e intenciones.

Con este recorrido crítico por algunas de las principales propuestas sobre las funciones del lenguaje hamos querido demostrar cómo cada escuela lingüística -psicologismo (Bühler), conductismo (Morris), teoría de la comunicación (Jakobson), estructuralismo funcionalista (Martinet), teoría sistémico-funcional (Halliday) y etnolingüística (Hymes)- acuña una peculiar definición de función externa: cualidad semántica del signo linguístico complejo, disposición para reaccionar ante los signos, focalización en un factor de la comunicación, determinante de la evolución y la estructura de las lenguas, componente abstracto del sistema semánticofuncional con reflejo en la estructura, combinación de factores del acto de habla...

El resultado es una multiplicidad de taxonomías en las que varía el número de las funciones (desde la única función esencial de Martinet hasta la abierta gama de posibilidades del último Hymes) y los criterios para su establecimiento (lingüísticos y no lingǘsticos, con marcas formales no características o como elaboraciones); ni siquiera existe un acuerdo sobre lo que son funciones y lo que son usos (algunos usos secundarios de Martinet son funciones para Jakobson o Halliday) y las jerarquizaciones son dispares (para Martinet, la función central es la comunicación; para Jakobson, Halliday o Hymes, las funciones confluyen en los textos, destacándose una de entre las demás).

y reflejo del pensamiento humano, dilícilmente puede ser subsumida por ninguna de las tres metafunciones, ya que ni se deriva de significado social alguno ni ligura ente las opciones de las clases de oración, en cl sentido defendido por Halliday (la función texlual, en cambio, posec un reflejo oracional con su distinción toma/rema). 
Finalmente, ien qué punto puede establecerse el límite del número de las funciones y/o usos si el lenguaje es capaz virtualmente de cumplir cualquier finalidad?; dónde se sitúan otras funciones y/o usos estudiados como la función mágica (Jakobson, 1960), la función mostrativa o deíctica (Araya, 1964), la función lúdica (García Calvo, 1958; D.François, 1972; Ynduráin, 1974; Eguren, 1975), la función ética -eufemismos, tabúes- de Kainz (Ynduráin, 1974), las funciones secundarias -métrica ,expresiva, prosódica y metafórica- de Guiraud (1968)...? El panorama de los estudios sobre las funciones del lenguaje permanece, en nuestra opinión, tan resbaladizo y confuso como imprescindible es su esclarecimiento.

\section{La autonomía de la estructura ${ }^{7}$}

Como adelantábamos en el anterior apartado, al menos dos de las escuelas funcionalistas de mayor implantación entroncan su noción de "función externa" con el nexo que liga las finalidades del lenguaje con sus funciones internas: la función de comunicación de Martinet determina la evolución y la estructura de las lenguas y las metafunciones de Halliday configuran el sistema linguístico. Para ambos, contrariamente a lo defendido por Chomsky (vid. apart.1), la explicación última del lenguaje humano se encuentra en pará qué sirve ${ }^{\text {. }}$.

Martinet (1960:; 222; 1964: 59) y sus seguidores (D. François, 1969: 157) sostiene la hipótesis de que las funciones del lenguaje articulan los criterios para el establecimiento de las funciones gramaticales. En concreto, los caracteres de la comunicación -mínimo esfuerzo, máxima comprensión...- soportan los perfiles de la estructura (oposición, discrección, solidaridad) y dan cuenta de la evolución de las lenguas (v.g., el rendimiento comunicativo de una oposición fonológica como causa de su mantenimiento o desaparición).

Halliday $(1970,1973,1975 b)$ conduce hasta su límite extremo la dependencia de la estructura lingüística con respecto a las funciones externas. Dentro de su teoría (vid. apart. $2 e$ ), los usos del lenguaje recogen un potencial de significación social que se sedimenta en tres metafunciones que, a su vez, segmentan el sistema lingǘstico en tres bloques formales cuya aparición en los textos es simultánea, "como los acordes de una fuga" (Halliday, 1973: 98): "la gramática tiene una base funcional; ha evolucionado como forma de contenido, como una representación del potencial de significación por medio del cual el lenguaje satisface sus diferentes funciones sociales".

Halliday percibe en la oración tres subsistemas la transitividad, el modo y la

7 Es evidente que las funciones del lenguaje encuentran vehículos formales dislintivos, entre otros, su plasmación en las modalidades de frase o clases de oración (vid., v.g., Hernándé, 1984 y García Calvo, 1958). Esta correspondencia no es, sin embargo, biunivoca: "las relaciones entre medios y fines son múliples en ambas direcciones, los mismos medios sirven en ocasiones fines diversos, y los fines son realizados por múltiples medios" (Hymes, 1964:5). En ningún momento negamos que las funciones del lenguaje muestren reflejos formales; lo que sostenemos es que existen parcelas estructurales aulónomas, sin un origen luncional decisivo.

${ }^{8}$ No son estos dos lingüistas los únicos representantes de tal actitud. Dik (1978, 1980) construye su gramática funcional sobre semejantes pilares; la teoría gramatical no debe explicar las reglas dul sistema en sí mismas, sino con respecto a su utilización, a sus finalidades. En este mismo espíritu, Kuno (1987) intenta derivar cicrtos principios formales de máximas funcionales. 
tematización- a los que enlaza con sus tres metafunciones -ideativa, interpersonal y textual, respectivamente-: la "gramática" de la transitividad hace referencia a los procesos, a los participantes en los mismos y a las circunstancias que los rodean; las funciones del habla y los papeles y actitudes sociales del hablante-oyente conforman la "gramática" del modo; la "gramática" del tema recoge el estatus de la oración y sus partes como unidades de comunicación, como mensajes (Kress, 1976: 20-31).

Esta partición no es innovadora. Se remonta a la tradicional subdivisión de la oración en tres niveles: estructura semántica (papeles temáticos), estructura gramatical (funciones sintácticas) y organización del enunciado (el hinomio tema/rema o tópico/comentario). La originalidad de Halliday estriba en otorgar a esta triple estructuración un, fundamento funcional.

Así, por ejemplo, en la oración "la policia detuvo a los terroristas ayer", "la policía" es el actor o el sujeto lógico (el agente de la acción), el sujeto gramatical (aquel del que se predica algo) y el tema o sujeto psicológico (el punto de partida conocido de lo que el hablante va a decir). En cambio, en la oración derivada de la anterior "ayer, los terroristas fueron detenidos por la policia", "ayer" es el tema, "los terroristas", el sujeto gramatical (como demuestra la concordancia) y "la policía", el agente (Halliday 1985: 32-37) 9.

Tanto la propuesta de Halliday como la de Martinet parecen, a primera vista, razonables. Sin embargo, un análisis cuidadoso nos revela algunos puntos oscuros en las mismas.

De las necesidades de la comunicación eficaz se derivan rasgos de la estrctura de las lenguas y de su evolución, probablemente, los senalados por Martinet; pero es ésta una visión parcial de la cuestión: otros criterios funcionales -como los procesos de memorización (vid. apart. 1) - juegan un papel, aún no precisado, en la configuración de la estructura lingüística; usos no comunicativos del lenguaje -v.g., el servir de soporte al pensamiento (vid. apart. 2)imponen severas restricciones sobre la forma de las gramáticas; las lenguas cambian en direcciones sorprendentemente divergentes bajo condiciones comunicativas semejantes y, en cualquier caso, estas modificaciones se hallan encauzadas por el tipo de gramáticas posibles, fijado en el código genético de la especie (Lightfoot, 1981).

Tampoco cabe duda de que se distinguen en la oración los tres niveles estructurales postulados por Halliday y de que éstos están dotados de un carácter esencial, quizás, universal. Más discutible es que el último de ellos la tematización, la función textual- seá equivalente a los otros dos. Halliday diseña sus metafunciones como abstractos componentes semántico-funcionales que reúnen el potencial significativo de los usos sociales. Pues bien, las metafunciones ideativa e interpersonal se atienen a esta definición, pero no así la función textual. Difícilmente pueden concebirse motivaciones semántico-funcionales (sociales) para la distinción tema/rema, los conectores lógicos, las relaciones anafóricas, etc. Resulta, entonces, que la supuesta metafunción textual no es tal, al menos en el sentido estricto que caracteriza a las otras dos: el ajustado esquema de Halliday muestra, por este flanco, una disarmonía que nos hace dudar de su viabilidad global (vid. apart. 2e).

Pero incluso en el supuesto de que los tres bloques estructurales que componen

${ }^{9}$ Halliday reconoce expresamente que estos (res niveles aparecen en Dancs (vid. Kress, 1976: 27). Dik (1978, 1980) distingue también entre funciones semánticas, sintácticas y pragmáticas. Para un análisis detallado de los tres tipos de sujelo -semántico, luncional y psicológico-vid. Lyons (1969). 
conjuntamente la oración (incluido el sistema de la tematización) pudieran explicarse funcionalmente, habría que dar cuenta de otras propiedades estructurales que no parecen satisfacer ninguna finalidad externa claramente discernible; por ejemplo, las interferencias entre los tres subsistemas, lo que, dentro de la GGT, se ha atribuido al componente transformacional, más concretamente, a las reglas de movimiento ${ }^{10}$. Veamos los siguientes datos:

(1) (i) Mi hermano me contó que había comprado libros

(ii) Mi hermano me contó qué había comprado

(iii) Libros, me contó mi hermano que había comprado

(iv) Mi hermano me contó qué había comprado libros

(v) Libros, me contó mi hermano que había comprado apanamentos

(vi) Mi hurmano me contó qué había comprado

(vii) Mi hermano me contó libros que había comprado

En (li), "libros" es el objeto sintáctico y semántico del verbo "comprar". En (1ii), "qué" aparece como objeto semántico de "comprar", pero su función sintácticáa es la de complementante (nexo funcional entre una oración matriz y otra incrustada). En (1iii), "libros" es, a la vez, tema y objeto semántico. Como puede apreciarse, nos encontramos ante casos de discordancia entre las funciones semánticas, las sintácticas y las tematizaciones, semejantes a las que recoge Halliday. El problema reside en por qué son agramaticales las oraciones de (1iv-vii) y gramaticales las de (1i-iii). En (1iv), "qué" y "libros" satisfacen ambos la misma función semántica de objetos de "comprar" (lo mismo sucede en (1v) con "libros" y "apartamentos"). En (1vi) y (lvii), "qué" y "libros" se han movido a la posición de objetos de "contar", manteniendo su primitiva función semántica de objetos de "comprar".

Parece, por tanto, que la ausencia de equivalencia entre los elementos lógicos, gramaticales y psicológicos de una oración está drásticamente constreñida: no puede desplazarse cualquier frase a cualquier posición. La versión actual de la GGT -la Teoría de la Rección y el Ligamiento (Chomsky, 1981, 1986; Riemsdijk y Williams, 1986)- explica este fenómeno, en parte ", por medio de un principio universal, el criterio temático:

(2) Una lrasc nominal léxica sólo puede ocupar una posición temática y cada posición temálica debe estar ocupada por una sola frase nominal léxica, donde posiciones temáticas son las depositarias de los papeles temáticos (agentc, pacientc, destinatario, locación...)

La gramaticalidad de (1i-iii) y la mala formación de (liv-vii) se deducen directamente de (2). En (1i-iii),"qué" y "libros" ocupan una sola posición temática, la de objeto semántico de "comprar" (las posiciones de complementante y de tema son no-temáticas, ya que nunca reciben papel temático: son posiciones periféricas a la red argumental de predicado verbal).

${ }^{10}$ Es marginal a nuestra discusión el que los elementos tematizados hayan sido desplazados a la posición de tema o generados directamente en la base (en este úlimo caso, una regla interpretativa cumpliría la misma liunción que las reglas de movimiento). "Tema" equivale a "tópico" en nuestra exposición y no debe confundirse con el papel temático de "tema", canónicamente asignado por el verbo a su objelo directo.

"La Teoría del Caso abstracto (cl. Chomsky, 1981, 1986; Riemsdijk y Williams, 1986) explica, además, la obligatoriedad de movimientos como la pasivización o la elevación del sujeto. 
Por el contrario, en (1iv-v), "comprar" asigna doblemente el mismo papel temático y en (lvivii), "qué" y "libros" reciben dos papeles temáticos distintos como objetos semánticos tanto de "comprar" como de "contar". La generalización que se extrae de (2) es que los movimientos sólo pueden realizarse a posiciones no-temáticas (en este caso, complementante y tema) y siempre que el vacío estructural (la huella) dejado al desplazarse no sea rellenado por ningún otro material léxico.

La propiedad de que los núcleos léxicos no puedan asignar más que una vez el mismo papel temático y de que las frases nominales reciban un unico papel temático quizás facilite la inteligibilidad de los enunciados; pero pueden imaginarse otras lenguas -no humanas- en las que sea posible una relación no unívoca entre papeles temáticos y posiciones temáticas. En consecuencia, el criterio temático, bajo esta formulación o modificado, es un rasgo peculiar de la estructura de las lenguas humanas, cuya base es biológica y no, funcional.

La discusión sobre las correspondencias entre los tres niveles de la oración, con soluciones como las que permite el criterio temático, marca una línea de nvestigación que favorece la autonomía de parcelas nucleares de la estructura gramatical. Un ejemplo en esta dirección ${ }^{12}$-a nuestro parecer, concluyente- nos lo ofrecen las relaciones de correferencia que mantienen en el seno de la oración las anáforas (reflexivos y recíprocos) y los pronombres (tónicos y átonos) con sus antecedentes, relaciones estudiadas, en el modelo de la Rección y Ligamiento, por la Teoría del Ligamiento.

(3) (i) Juan (i) dijo que $[(0)$ Pcdro lo (i/j) alcitaría].

(ii) Juan dijo que [Pedro (i) se (i) afeitaríal

(iii) *Juan dijo que |Pedro (i) lo(i) alcitaría|

(iv) "Juan (i) dijo que [Pedro sc (i) afcilaría|

(4) (i) Los chicos (i) escucharon $[(F N)$ mis hislorias sobrc cllos (i/j)|

(ii) Los chicos escucharon |mis (i) historias sobre mí mismo (i)]

(iii) ${ }^{*}$ Los chicos escucharon [mis (i) historias sobre mi(i)]

(iv) *Los chicos (i) escucharon [mis historias sobre sí mismos (i)]

(5) (i) María (i) pensaba que [(O) Ana estaba [(FA) enamorada de ella (i/j)]

(ii) María pensaba que |Ana (i) estaba [enamorada de si misma (i)l|

(iii) *María pensaba que |Ana (i) eslaba |enamorada de clla (i)||

(iv) *María (i) pensaba que [Ana cstaba |enamorada de sí misma(i)|]

(6) (i) Arturo (i) se asombró de que [(O) Manuel conversara [(FP) con él (i/j)\|]

(ii) Arturo se asombró de que |Manucl (i) conversara |consigo mismo (i)||

(iii) *Arturo se asombró de que [Manuel (i) conversara |con él (i)]]

(iv) *Arturo (i) se asombró de que [Manuel conversara |consigo mismo (i)|]

De una primera lectura de las oraciones de (3)-(b), donde la identidad de índices refleja correferencia, extraemos las siguientes observaciones descriptivas: (a) las anáforas y los pronombres se distribuyen complementariamente en cuanto a la búsqueda de su antecedente en la oración; de manera intuitiva, los pronombres lo encuentran "más lejos" y las anáforas,

12 Todos los módulos o subteorías del paradigma de la Rección y cl Ligamiento hubieran servido igualmente para nuetros propósitos. Ya Chomsky, en el modelo estándar (1979: 67-69), aduce, como prueba de la autonomía de la gramálica con respecto a las funciones externas, el hecho de que las reglas sean dependientes de la estructura: una lengua funcionaría mucho mejor incluso, a efectos de la comunicación, con reglas independientes de ha estructura. 
"más cerca"; (b) 0 y FN parecen constituir los límites de esta distribución ${ }^{13}$.

La Teoría del Ligamiento formula la naturaleza de estas relaciones por medio de dos principios o máximas de buena formación (prescindimos del principio $\mathrm{C}$, que tratá de las expresiones referenciales, por ser irrelevante para nuestros propósitos):

(i) Principio A: una anáfora está ligada en su caacgoría recctora

(ii) Principio B: un pronombre está libre en su calcgoría rectora

El conjunto de definiciones básicas para interpretar (7) queda establecido en (8) ${ }^{4}$ :

(8) (i) A liga a B si A manda-c (mando de constituyentes) a B y A está coindizada (cs correferente) con B

(ii) A manda-c a $B$ si del primer nudo ramificante del que pende $A$ pende también $B$

(iii) La calegoría rectora de $A$ es la mínima proyección máxima que contenga a $A$, a su rector y a su objeto (por tanto, sólo $O$ y $F N$ adquieren la condición de calcgorías rectoras, ya que son las únicas frases máximas que contiencn un sujeto: "Pedro" y "mis", respectivamente, en (3) y (4)).

Los datos quedan, así, esclarecidos. Las oraciones de (i-ii) son gramaticales porque los pronombres no son correferentes con ningún elemento que los mande-c dentro de su categoría rectora $(0$ o FN); las anáforas, por su parte, están correctamente ligadas dentro de su categoría rectora. La mala formación de los casos de (iii-iv) se produce al darse la situación contraria, infringiéndose los principios A y B de (7) (el subíndice $\mathrm{j}$ indica la posibilidad de referencia libre para los pronombres; las anáforas, en cambio, necesitan obligatoriamente un antecedente).

Estos principios, abstractos y simples al mismo tiempo, quizás colaboren en una mejor inteligibilidad de los enunciados o agilicen los procesos de memorización. Pero, incluso en este supuesto, quedan sin respuesta preguntas cruciales: ¿por qué se sujetan a configuraciones jerárquicas tan estrictas como el mando-c o la rección?, es decir, ¿cúal es la causa de que los antecedentes estén "más altos" estructuralmente?; ¿por qué se distribuyen las anáforas y los pronombres de esta manera y no a la inversa?; ¿a qué se debe el que las categorías rectoras sean 0 y FN?. La hipótesis más plausible es que estos principios -y/u otros parecidos-, inscritos en el código genético de la especie, forman parte de un conjunto de propiededes definidoras del lenguaje humano, hipótesis que se ve confirmada con la constatación de que las lenguas estudiadas hasta el momento los respetan con escasas variaciones (significativamente, en el aprendizaje de lenguas no maternas estos fenómenos se pasan por alto, se dan por supuestos).

\section{Conclusiones}

De nuestra exposición no debe deducirse una descalificación global ni de las teorías sobre las funciones del lenguaje ni de la hipótesis de que éstas condicionen la estructura

${ }^{13}$ Claro está que estos datos son sólo orientativos, y en absoluto cubren todas las relaciones del ligamiento.

14 Véase Giorgi (1987) para la noción de mando-c de (8ii) y Lasnik y Uriagereka (1988) para la de SUJETO accesible y Chomsky (1986b) para la de rección en (8iii). 
lingüística. Aspiramos, tan sólo, a haber precisado la transcendencia y las limitaciones de los presupuestos funcionalistas dentro de la lingüística teórica.

Ciertamente, sostenemos el mismo punto de vista que Hymes (1964:5): "el estudio estructural del lenguaje y la comunicación, para insertarse en la vida social, no puede efectuarse de otra manera si no es cogiendo este toro (el de las funciones externas) por los cuernos". Imágenes taurinas aparte, resultan sumamente prometedoras sus teorías sobre la competencia comunicativa y la adecuación explicativa existencial, que trasladan al terreno de la sociolingüística conceptos surgidos en el seno de la GGT. En concreto, los factores constituyentes del acto de habla -por ahora, una mera "guía heurística" para las descripcionesbien podrían convertirse, refinados y correctamente parametrizados, en rasgos universales de la dimensión social del lenguaje con una representación última en el código genético de la especie. Igualmente interesante es el intento de Halliday de explicar el papel del lenguaje en el proceso de sociabilización -adquisición de valores socio-culturales concretos- por medio de sus tres metafunciones que segmentan la estructura lingüística.

El problema estriba en que hasta que no se conozcan en detalle los mecanismos formales con los que se materializan las funciones y se descubran los vínculos que engarzan estos procedimientos con otros no lingüísticos, los estudios sobre las funciones externas difícilmente podrán sobrepasar el nivel de reveladoras intuiciones. En este punto, parece justificada la estratégica abstracción que la GGT efectúa de semejantes fenómenos: "en la medida en que contemos con una teoría explícita de la competencia, podemos intentar esbozar modelos de realización para mostrar cómo es usado este conocimiento" (Chomsky, 1980:235-237).

En cuanto a la interdependencia entre las funciones internas y las externas, las necesidades de la comunicación eficaz (Martinet) y de la transmisión de la cultura (Halliday) así como los imperativos de la memorización y del procesamiento de los enunciados han podido configurar, al menos en una parte, la forma de las gramáticas en las lenguas humanas en el momento de la adopción del lenguaje por parte de la especie. Más difícil parece el determinar en qué aspectos y en qué medida se produjo esta influencia: si aceptamos una teoría evolucionista mixta entre la variación al azar (las mutaciones) y la selección natural, los criterios funcionalistas actuarían como filtros que favorecen ciertas opciones producidas pero no como las causas de que éstas se produzcan (Ridley, 1985).

Factores como los señalados, sin embargo, juegan tan sólo un papel de disparadores o incentivadores en el crecimiento de los individuos concretos, en cuyo caso tayy que apelar, más bien, a consideraciones biológicas (genéticas), si queremos explicar la rapidez, uniformidad y "corrección" con que se adquieren las lenguas.

\section{Referencias bibliográficas}

Araya Goubet, G. (1964), "Dimensiones semánticas del lenguaje", Mapocho, II, ṇ̂, págs. 179193.

Bühler, K. (1934), Sprachtheorie, Jena, Fischer (Trad. cast.: Teoría del lenguaje, Madrid, Alianza, 1979).

Chomsky, N. (1968), Language and mind, Harcourt.

Chomsky, N. (1975), Reflections on language, Pantheon. 
Chomsky, N. (1977), Dialogues avec Mitsou Ronat, París, Flammarion (Trad. cast.: Conversaciones con Noam Chomsky, Barcelona, Garnica, 1978).

Chomsky, N. (1980), Rules and representations, Columbia UP (Trad. cast.: Reglas y representaciones, México, Fondo de Cultura Económica, 1983).

Chomsky, N. (1981), Lectures on government and binding, Dordrecht, Foris.

Chomsky, N. (1982), The generative enterprise. A discussion with Riny Huyberts \& Hank van Riemsdijk (1979-1980), Dordrecht, Foris.

Chomsky, N. (1986a), Knowledge of language: its nature, origin and use, Nueva York,

Chomsky, N. (1986b), Barriers, Cambridge, MIT Press.

Chomsky, N. y Piaget, J. (1979), Théories du langage, théories de l'apprendissage, París, Editions du Seuil (Trad. cast.: Teorías del lenguaje. Teorias del aprendizaje, Barcelona, Crítica, 1983).

Dik, S. C. (1978), Functional grammar, Amsterdam, North Holland Lingüistic Series 37 (Trad. cast.: Gramática funcional, Madrid, SGEL, 1981).

Dik, S. C. (1980), "Seventeen sentences: basic principles and applications of functional grammar", en E. A. Moravcsik y J. R. Wirth (eds.) Syntax and Semantics. Current approaches to syntux 13, Nueva York, Academic Press, págs. 45-75.

Eguren, L. J. (1988), Aspectos lúdicos del lenguaje. La jitanjáfora, problema lingüístico, Servicio de Publicaciones de la Universidad de Valladolid.

Francois, D. (1969), "Fonctions du langage", en La linguistique. Guide Alphabétique, París, Denoël (Trad. cast.; La linzüística. Guía ulfabética, Barcelona, Anagrama, págs. 153160)

François, F. (1965), "El lenguaje y sus funciones", en El lenguaje, la comunicación. Tratado del lenguaje I (dir. A. Martinet), Buenos Aires, Nueva Visión, págs. 21-35.

García Calvo, A. (1958), "Funciones del lenguaje y modalidades de la frase", Estudios Clásicos, IV, 24, págs. 329-350.

Gardiner, A. (1951), The theory of speech and language, Oxford, Clarendon Press.

Giorgi, A. (1987), "La noción adecuada de mando-c y la teoría del ligamiento: Pruebas a partir de los sintagmas nominales", en V. Demonte y M. Fernández Lagunilla (eds.) Sintaxis de las lenguas románicas, Madrid, El Arquero.

Guiraud, P. (1968), "Les fonctions secondaires du langage",Le langage. Encyclopédie de la Pléiade (ed. A. Martinet), Bélgica, Gallimard, págs. 435-512.

Halliday, M. A. K. (1970), "Language structure and language function", en J. Lyons, New horizons in linguistics, Penguin, págs. 140-165.

Halliday, M. A. K. (1973), Explorations in the functions of language, Londres, Edward Arnold. (Trad. cast.: Exploraciones sobre las funciones del lenguaje, Barcelona Editorial Médica y Técnica, 1982).

Halliday, M. A. K. (1975a), Learning how to mean. Explorations in the developement of language, Nueva York, Academic Press (Trad. cast.: "Aprendiendo a conferir significado", en E. H. y E. Lenneberg, Fundamentos del desarrollo del lenguaje, Madrid, Alianza, págs. 239-268).

Halliday, M. A. K. (1978), Language as social semiotic: The social interpretation of language and meaning, Londres, Edward Arnold (Trad. cast.: El lenguaje como semiótica social. La interpretación social del lenguaje y del significado, México, Fondo de Cultura Económica, 1982). 
Halliday, M. A. K. (1985), An introduction to functional grammar, Londres, Edward Arnold. Halliday, M. A. K. y Martin, J. R. (eds.) (1981), Reading in systemic linguistics, Londres, Batsford Academic.

Hernández Alonso, C. (1984), Gramática funcional del español, Madrid, Gredos.

Hymes, D. (1964), "Toward Ethnography of Communication", en Gumperz y Hymes, The Ethnography of Communication (vers. cit. D. Hymes, Foundations in Sociolinguistics. An ethnographic approach, Filadelfia, págs. 3-27).

Hymes, D. (1967), "Models of the interaction of language and social setting", Journal of Social Issues, 23 (vers. cit. Hymes y Gumperz, Directions in Sociolinguistic. The Ethnogruphy of Communication, Nueva York, Holt, Rinehart y Winston, 1972, págs. 35-71).

Hymes, Dell (1970), "Linguistic theory and the functions of speech", International days in Sociolinguistics, Roma (ver. cit. Hymes, 1974, págs. 145-178).

Hymes, D. (1972), "On comunicative competence", en J. B. Pride y J. Holmes, Sociolinguistics. Selected Readings, Penguin, págs. 269-293).

Hymes, D. (1984), Vers la competence de communication, París, Hatier.

Jakobson, R. (1960), "Linguistic and poetics", en T. A. Seabeok (ed.), Style in language, Cambridge, MIT Press (Trad. cast.: "Lingüística y poética", Ensayos de lingüística general, Barcelona, Seix barral, 1981, 347-195).

Kress, G. (ed.) (1976), Halliday: system and function in language. Selected Papers, Londres, Oxford University Press.

Kuno, S. (1987), Funtional Syntax, University of Chicago Press.

Lasnik, H. y Uriagereka, J. (1988), $A$ course in GB syntax, MIT Press.

Lightfoot, D. (1981), "Explaining syntactic change", en N. Hornstein y D. Lightfoot (eds.) Explanation in linguistic. The logical problem of langrage acquisition, Londres, Longman, págs. 209-240.

Lyons, J. (1969), Introduction to theoretical linguistics, Cambridge, CUP (Trad. cast.: Introducción en la lingǘstica teórica, Barcelona, Teide, 1971).

Malinowsky, B. (1923), "The problem of meaning in primitive languages", en C. K. Ogden e I. A. Richards, The meaning of meaning, Londres, Kegan Paul (Trad. cast.: El significado del significado, Buenos Aires, Paidós, 1964, págs. 312-360).

Martinet, A. (1960), Eléments du linguistique générale, París, Arman Culin (Trad. cast.: Elementos de lingüistica general, Madrid, Gredos, 1974).

Martinet, A. (1962), A functional view of language, Oxford University Press (Trad. cast.: El lenguaje desde el punto de vista funcional, Madrid, Gredos, 1971).

Martinet, A. (1964), Economie des changements phonétiques. Traité de phonologie diachronique, A. Francke AG Verlag Bern. (Trad. cast.: Economía de los cambios fonéticos. Tratado de fonología diacrónica, Madrid, Gredos, 1974).

Martinet, A. (1985), Syntaxe générale, París, Armand Colin.

Martínez Bonati, F. (1960), La estructura de la obra literaria, Barcelona, Seix Barral.

Morris, C. (1946), Signs, langage and behaviour, New York, Prentice-Hall (Trad. cast.: Signos, lenguaje y conducta, Buenos Aires, Losada, 1962).

Richards, I. A. (1972), "Functions of and factors in language", Journal of Literary Semantics, The Hague, Mouton, págs. 25-40.

Ridley, M. (1985) The problems of evolution, Oxford University Press (Trad. cast.: La evolución y sus problemas, Madrid, Pirámide, 1987). 
Riemsdijk, H. van \& Williams, E. (1986), Introduction to the theory of grammar, Cambridge, the MIT Press.

Riffaterre, M. (1971), Essais de stylistique structurale, París, Flammarion (Trad. cast.: Ensayos de estilística estructural, Barcelona, Seix Barral).

Searle, J. R. (1969), Speech Acts, Cambridge (Trad. cast.: Actos de habla, Madrid, Cátedra, $1980)$.

Trujillo, R. (1976), "Semántica y funciones del lenguaje", en Elementos de semántica estructural, Madrid, Cátedra, págs. 17-36.

Ynduráin Hernández, F. (1974), "Para una función lúdica en el lenguaje", en Doce ensayos sobre el lenguaje, Madrid, Rioduero, págs. 215-227. 